\title{
EDITORIAL
}

\section{Preface for the special issue on light metals as biomaterials}

\author{
Guang-Ling SONG ${ }^{1}$ and Rong-Chang ZENG $^{2}$ \\ 1 Oak Ridge National Laboratory, Oak Ridge TN37831, USA \\ 2 Shandong University of Science and Technology, Qingdao 266590, China
}

(C) Higher Education Press and Springer-Verlag Berlin Heidelberg 2014

$\mathrm{B}$ iomaterials research is one of the most active fields with many novel techniques and products emerging to alleviate pain and suffering. Metallic biomaterials have high strength and toughness in comparison to polymers and ceramics. These advantages make them suitable for load-bearing orthopedic implants and coronary stents. Nowadays, more and more biocompatible light metals, such as titanium alloys and magnesium alloys, are attracting researchers' attention for implant applications. For example, titanium alloys with outstanding corrosion resistance and excellent biocompatibility have been widely utilized as permanent implants, while magnesium alloys have been regarded as revolutionary biodegradable metals for biomedical applications due to their unique degradation behavior in the human body and outstanding mechanical compatibility with human bones. To provide a basis for future continued achievements in this forefront of materials research science, it is important to have a special collection of recent studies by active researchers in this field.

This special issue, Light Metals as Biomaterials, contains two reviews and eight research papers. The development of biomedical titanium alloys is reviewed with a focus on the improvement in mechanical biocompatibility by alloy design, metallurgical processing, mechanical treatments, and microstructure modification. Papers in the special issue also cover the progress and development of biomedical magnesium alloys. Since rapid corrosion is the major problem with biomedical magnesium alloys, the influences of alloy microstructure and media conditions on the corrosion of pure magnesium and its alloys are an area of focus in this collection. Reports of efforts for improving corrosion resistance through alloying, surface modification, and coating for biomedical magnesium alloys are also included. We believe that the selected 10 articles cover most of the key topics in the light metal biomedical implant field and reflect the status and trends of recent research.

We thank the contributors for sharing their impressive research results in this special issue.<smiles>C#CC1=CCCC1</smiles>

Guang-Ling SONG,

Oak Ridge National Laboratory, Oak Ridge TN37831, USA

and

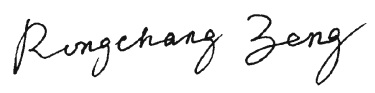

Rong-Chang ZENG,

Shandong University of Science and Technology, Qingdao 266590, China

September 1st, 2014 